\title{
ANALISIS BAHAN KIMIA BERBAHAYA PADA KRIM PENCERAH WAJAH YANG BEREDAR DI KOTA SAMARINDA
}

\author{
Muhammad Ardan*, Risna Agustina, Muhammad Amir Masruhim \\ Laboratorium PenelitiandanPengembangan FARMAKA TROPIS \\ Fakultas FarmasiUniversitasMulawarman, Samarinda, Kalimantan Timur \\ *Email: muhammadardan858@yahoo.co.id
}

\begin{abstract}
ABSTRAK
Pemakaian merkuri dan hidrokuinon dalam krim pemutih kulit dapat menimbulkan perubahan warna kulit yang dapat menyebabkan bintik hitam pada kulit setelah penghentian pemakaian secara permanen, bahkan pemakaian dalam jangka waktu lama dapat menyebabkan kerusakan permanen otak, ginjal, kanker dan gangguan perkembangan janin. Tujuan penelitian adalah untuk mengetahui apakah ada senyawa merkuri dan hidrokuinon yang ditambahkan pada sediaan krim pencerah wajah yang beredar di Kota Samarinda. Metode penelitian dilakukan secara kualitatif, uji merkuri dilakukan sengan reaksi warna dengan penambahan KI 0,5N. Hasil positif merkuri berupa larutan berwarna orange sampai merah bata. Sedangkan uji hidrokuinon secara semi kuantitatif dengan perhitungan nilai Rf pada KLT. Berdasarkan hasil uji diperoleh dari 6 sampel yang terdiri atas 4 sampel tanpa nomor registrasi dan 2 sampel dengan nomor registrasi palsu. seluruhnya positif mengandung merkuri dan dari semua sampel tersebut menunjukkan hasil negatif kandungan hidrokuinon.
\end{abstract}

Kata Kunci : Krim, merkuri, hidrokuinon, KLT

\section{ABSTRACT}

The use of mercury in whitening cream can cause changes in skin color which can cause black spots on the skin after halting the use of permanently, even the use in the long term can cause permanent damage the brain, kidneys, cancer and disorders of fetal development. The purpose of the research is to find out if there is mercury compounds and hydroquinone is added to the cream lightening that circulated in the city of Samarinda. The study was conducted in a qualitative test, the mercury will be tested by the reaction of the color with the addition of KI $0,5 N$. The positive results of mercury in the form of the orange to red brick. The test of hydroquinone will be tested by half of quantitative method with the applicability to the calculation of the Rf in TLC. Based on the test results obtained from the 6 samples consists of 4 samples without registration number and 2 samples with registration number. All samples shows negative results of hydroquinone.

The key : Cream, mercury, hydroquinone, TLC.

Prosiding Seminar Nasional Kefarmasian Ke-3, 


\section{PENDAHULUAN}

Sediaan kosmetik yang biasa digunakan untuk diaplikasikan ke wajah adalah krim pencerah wajah. Banyak wanita maupun pria yang menginginkan kulit wajah yang cantik, putih dan bersih, tanpa memperhatikan keamanan kandungan bahan yang dipakai. Bahan yang dilarang untuk ditambahkan ke dalam sediaan krim pencerah wajah yang sering ditemukan adalah merkuri, hidrokuinon dan asam retinoat. Beberapa kosmetik dapat ditemukan berbagai bahan kimia yang berbahaya bagi kulit, seperti merkuri, hidroquinon, asam retinoat dan zat warna sintetis seperti Rhodamin B dan Merah K3. Bahan-bahan ini sebetulnya telah dilarang penggunaannya sejak tahun 1998 melalui Peraturan Menteri Kesehatan RI No. 445/MENKES/PER/V/1998 ${ }^{1}$.

Hasil pengawasan Badan POM selama tahun 2014 diidentifikasi pada 68 kosmetika mengandung bahan berbahaya, terdiri dari 32 jenis kosmetik luar negeri dan 36 kosmetik dalam negeri. Untuk itu BPOM mengeluarkan peringatan publik tentang kosmetik berbahaya, dengan tujuan agar masyarakat tidak menggunakan kosmetika tersebut karena dapat membahayakan kesehatan. ${ }^{2}$

Mengingat banyaknya temuan kosmetik krim mengandung bahan kimia yang ditambahkan khususnya merkuri dan hidrokuinon, sehingga perlu dilakukan analisis atau pengujian terhadap sediaan krim pencerah wajah yang beredar di daerah Kota Samarinda demi keamanan dan pencegahan terhadap bahaya akibat dari sediaan krim pemutih wajah yang diduga mengandung merkuri dan hidrokuinon.

\section{METODE PENELITIAN}

\section{Bahan}

Aquades, $\mathrm{CH}_{3} \mathrm{COOH}, \mathrm{HCl}$, asam nitrat, hidrokuinon, $\mathrm{KI}_{2}$, kertas saring, krim pencerah wajah, pipa kapiler, merkuri, metanol, N-heksan, Plat KLT.

\section{Peralatan}

chamber glass, erlenmeyer, labu takar, lampu UV 254 dan 366, mikropipet, penangas air, pipa kapiler, pipet tetes, pipet volume, pro pipet, timbangan analitik.

\section{Prosedur}

\section{Pengambilan sampel}

Sampel berupa 6 buah krim pencerah wajah dengan merk yang berbeda-beda yang dipilih di beberapa toko kosmetika di kota samarinda.

\section{Pengujian merkuri}

Ditimbang dengan saksama sampel sebanyak $0,1 \mathrm{~g}$ dan ditambah aquadest sebanyak 25 $\mathrm{mL}$. Setelah itu ditambahkan $20 \mathrm{~mL}$ larutan aqua regia $(\mathrm{HCl} \mathrm{p}: \mathrm{HNO} 3 \mathrm{p}=3: 1)$, dan ditempatkan pada hot plate selama 3 jam, didinginkan dan disaring. Kemudian didapatkan larutan sampel.

Dimasukkan $1 \mathrm{ml}$ larutan uji kedalam Erlenmeyer, kemudian ditambahkan 1 sampai 2 tetes larutan KI 0,5 N, setelah itu diperhatikan dengan saksama, hasil menunjukkan positif jika warna larutan menjadi merah bata-orange. 


\section{Pengujian hidrokuinon}

Ditimbang dengan teliti sbanyak $2 \mathrm{~g}$ sampel, kemudian dimasukkan kedalam erlenmeyer, ditambahkan etanol (96\%) sebanyak $15 \mathrm{~mL}$, dihomogenkan diatas penangas air suhu $60^{\circ} \mathrm{C}$ selama 10 menit, kemudian didinginkan dan disaring menggunakan kertas saring, filtrat digunakan sebagai larutan uji.

Pengujian dilakukan menggunakan metode $\mathrm{KLT}$ dengan eluen $\mathrm{CH} 3 \mathrm{COOH}$ : toluene (2:8). Siapkan Plat KLT dengan ukuran 20 x $20 \mathrm{cmn}$ kemudiandiaktifkan didalam oven dengan suhu $105^{\circ} \mathrm{C}$ selama 30 menit, tandai batas atas dan batas bawah plat KLT masingmasing $0,5 \mathrm{~cm}$. Ditotolkan sampel dan pembanding pada plat KLT menggunakan pipa kapiler, kemudian dimasukkan kedalam eluen dan didiamkan hingga batas atas, setelah itu dikeringkan dan disinari dengan lampu UV 254 dan $366 \mathrm{~nm}$, dihitung nilai Rf dan di analisis.

\section{HASIL DAN PEMBAHASAN}

\section{HASIL UJI MERKURI}

Tabel 1. Hasil analisis kualitatif merkuri

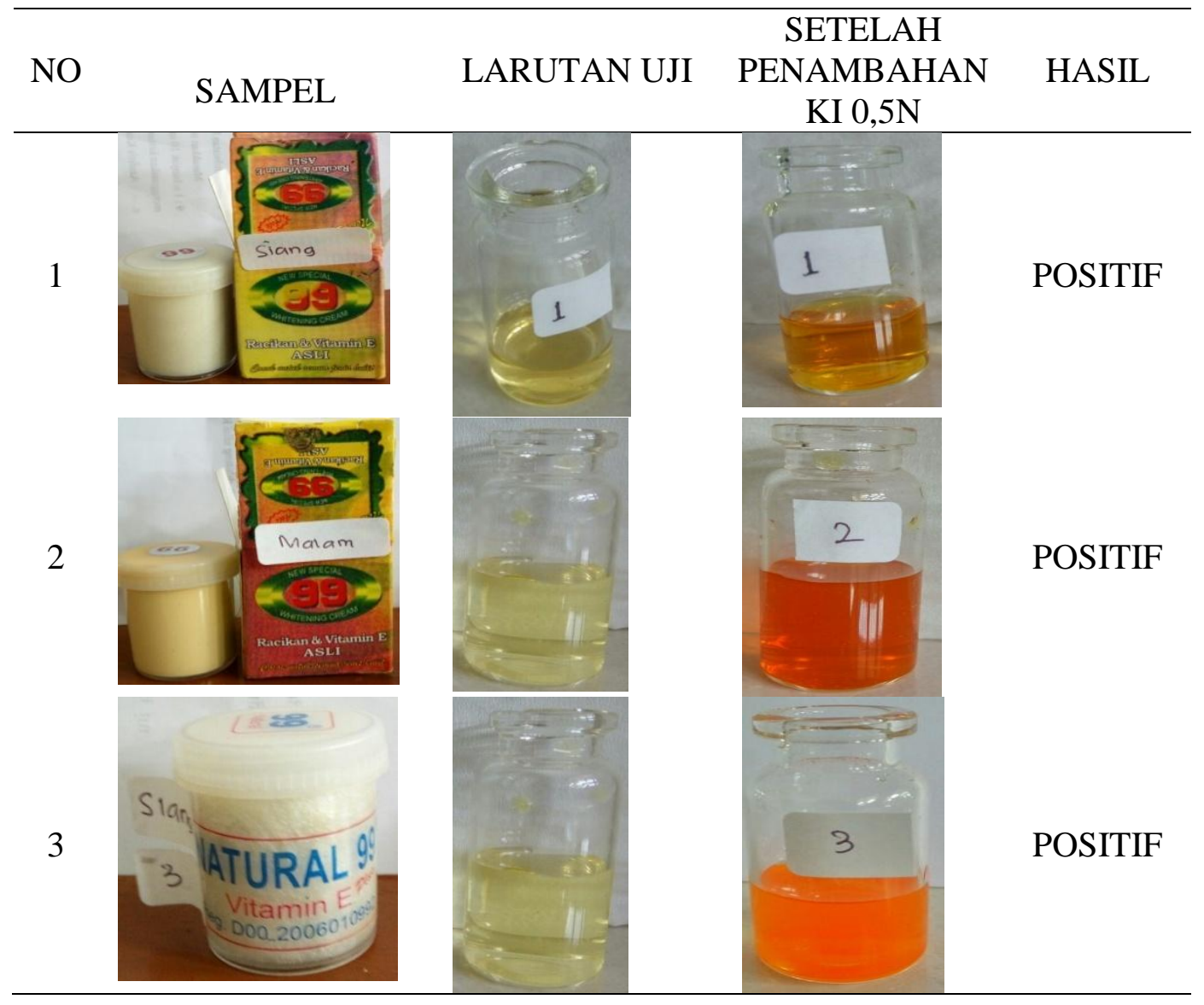




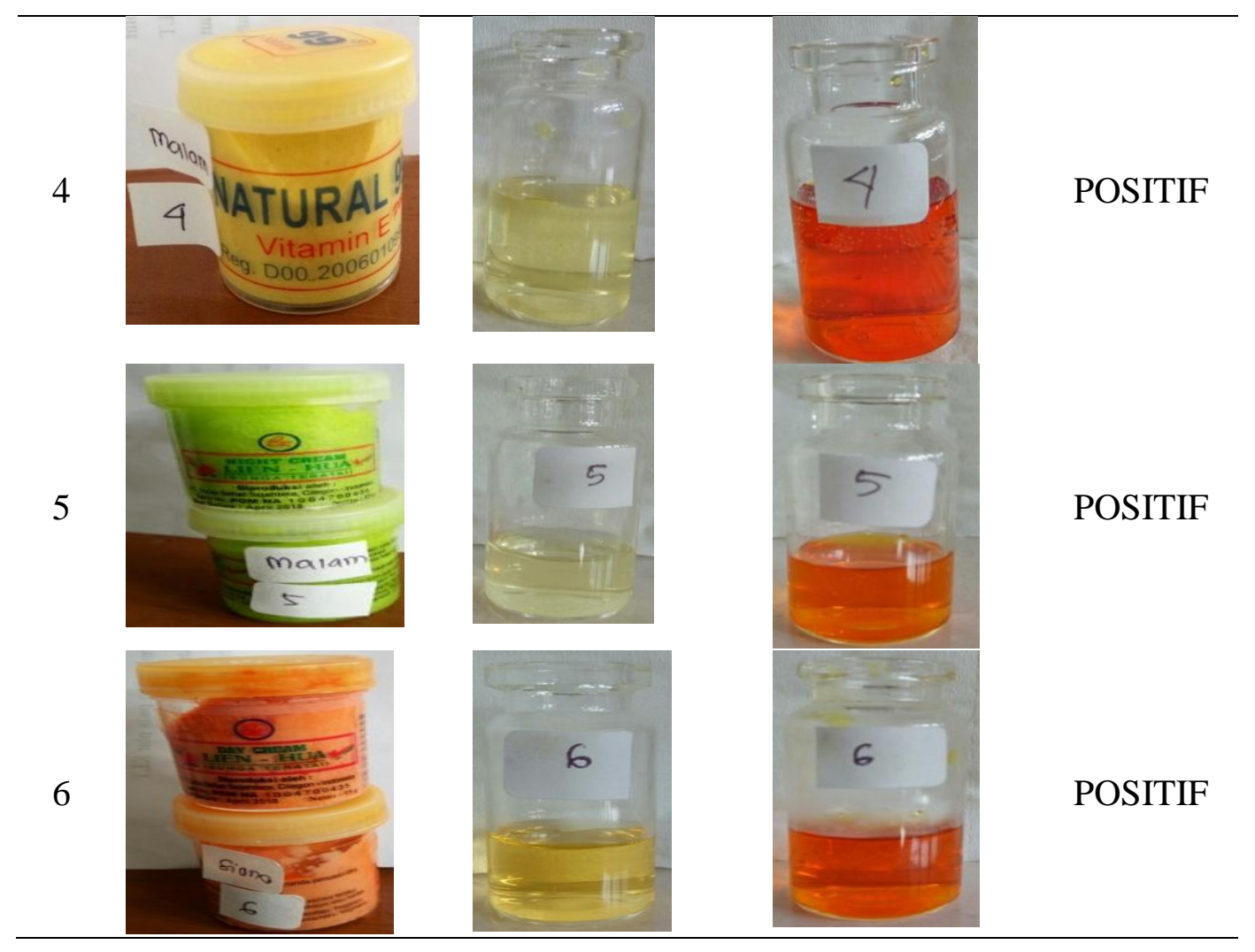

\section{HASIL UJI HIDROKUINON}

Tabel 2. Hasil analisis kualitatif hidrokuinon

\begin{tabular}{cccccc} 
NO & ELUEN & UV 254 366 & NILAI Rf & HASIL \\
\hline $\begin{array}{c}\text { TOLUEN : } \\
\text { CH3COOH } \\
(1: 9)\end{array}$ & & & & \\
\\
$1 \quad$ Rf BAKU 0,67
\end{tabular}



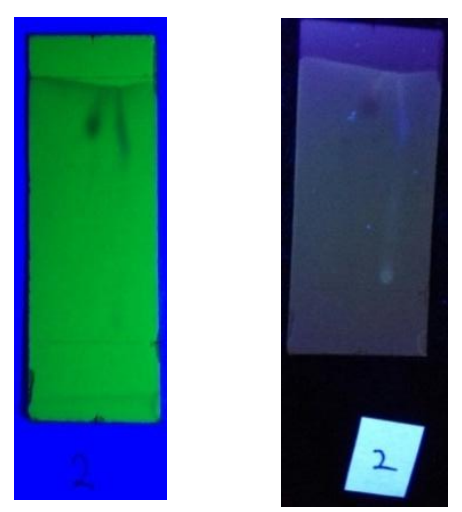

0,58 NEGATIF
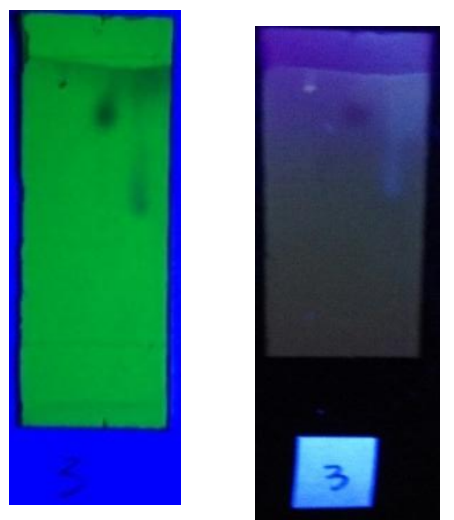

0,4 NEGATIF

3
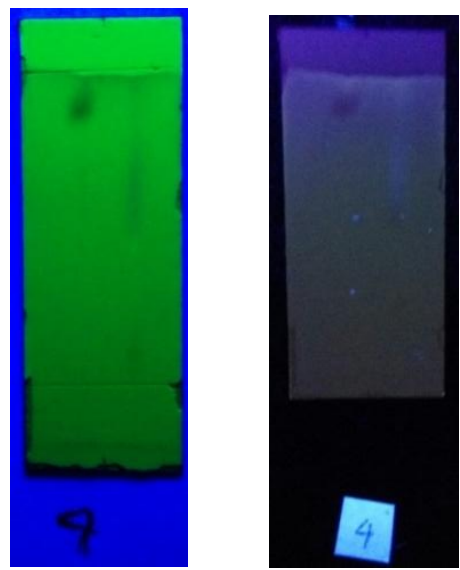

0,49

NEGATIF

4

Prosiding Seminar Nasional Kefarmasian Ke-3, 

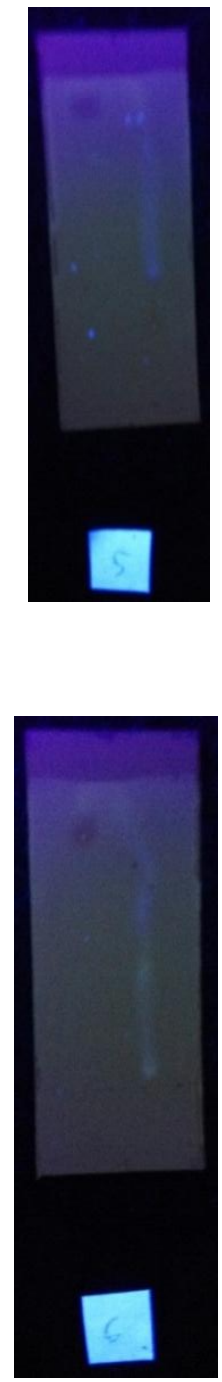

\section{Pembahasan}

Data tabel diatas menujukkan hasil analisis kualitatif senyawa merkuri dan hidrokuinon pada sampel krim pencerah wajah yang beredar di kota Samarinda. Sampel yang diperoleh dari pedagang kosmetik di pasaran tersebut di pilih berdasarkan aspek penduga adanya kandungan senyawa kimia berbahaya yang ditambahkan pada sediaan agar memiliki efek yang lebih cepat dan instan sebagai pencerah wajah, yaitu sampel yang tidak memiliki nomor izin dari BPOM ataupun yang memiliki nomor izin BPOM palsu. Selain itu juga sampel diambil berdasarkan karakteristik fisik dari sediaan krim yang meliputi bau menyengat, tekstur dan warna yang tidak homogen. ${ }^{3}$

Sampel yang diuji terdiri atas 6 merk sediaan, yaitu krim 99 Siang,krim 99 Malam, Lien Hua Siang, Lien Hua Malam, krim 99 Natural Siang, dan krim 99 Natural Malam. Dari sampel tersebut, 4 diantaranya memiliki nomor registrasi BPOM yang palsu dan 2 sampel lainnya tidak memiliki nomor registrasi BPOM. 
Menurut Dr. Retno I. Tranggono, SpKK menyebutkan bahwa krim yang mengandung merkuri, awalnya memang terasa manjur dan membuat kulit tampak putih dan sehat. Tetapi lama-kelamaan, kulit dapat menghitam dan menyebabkan jerawat parah. Selain itu, pemakaian merkuri dalam jangka waktu yang lama dapat mengakibatkan kanker kulit, kanker payudara, kanker leher rahim, kanker paru-paru, dan jenis kanker lainnya. ${ }^{4}$

Hidrokuinon termasuk golongan obat keras yang hanya dapat digunakan berdasarkan resep dokter. Penggunaan hidrokuinon lebih dari 2\% adalah sebagai tambahan krim pemutih kulit. Bahaya pemakaian obat keras ini tanpa pengawasan dokter dapat menyebabkan iritasi kulit, kulit menjadi merah dan rasa terbakar. Hidrokuinon juga dapat menyebabkan kelainan pada ginjal (nephropathy), kanker darah (leukemia) dan kanker sel hati (hepatocelluler adenoma).

Uji kualitatif merkuri dengan KI 0,5N menunjukkan hasil positif dengan terbentuknya warna larutan orange hingga merah bata. Sebelum sampel diuji secara kualitatif, terlebih dahulu dilakukan pengolahan sampel dengan cara digesti basah dengan menggunakan asam kuat yaitu $\mathrm{HCl} \mathrm{p}$ dan $\mathrm{HNO} 3 \mathrm{p}$ dengan perbandingan 3:1. Campuran kedua larutan diatas lebih dikenal sebagai aqua regia. Larutan aqua regia ini merupakan larutan digesti basah yang dipakai karena sifat aqua regia yang dapat melarutkan logam dan dengan proses yang lebih cepat $^{5}$. Digesti basah menggunakan aqua regia dilakukan diatas hot plate pada suhu $\pm 95^{\circ} \mathrm{C}$ selama 3 jam dalam Erlenmeyer yang dilakukan di dalam lemari asam. Pemilihan cara penyiapan sampel dengan digesti basah didasarkan pada sifat $\mathrm{Hg}$ yang mudah menguap ${ }^{6}$. Sampel uji kemudian di tetesi dengan larutan KI 0,5\% dimana hg akan bereaksi menjadi HgI2 yang ditandai dengan teradinya perubahan warna larutan menjadi merah bata sampai orange.

Sedangkan uji kualitatif hidrokuinon menggunakan metode KLT. Dari analisis identifikasi hidrokuinon pada krim pencerah wajah, dimana untuk mengetahui kandungan hidrokuinon tersebut diatas dapat dianalisa dengan cara identifikasi dengan metode Kromatografi Lapis Tipis. Jika bercak pada baku pembandingnya sejajar dengan sampel maka sampel tersebut mengandung hidrokuinon. Ternyata dari hasil analisis yang dilakukan, harga Rf pada larutan sampel jauh berbeda dengan harga Rf pada larutan baku pembandingnya, dimana pada prinsipnya sampel ditotolkan pada plat tipis . Bila noda telah kering plat diletakkan secara vertikal dalam bejana yang terdapat fase gerak Toluen : Asam asetat glasial (8:2), maka pemisahan kromatografi penaikan akan diperoleh.

Dalam hasil pengujian diperoleh hasil dari 6 sampel yang ada, seluruhnya menunjukkan hasil positif mengandung senyawa merkuri dimana dari semua sampel tersebut berwarna orange dan merah bata setelah diberikan beberapa tetes $\mathrm{KI} 0,5 \mathrm{~N}$ dan dari semua sampel tersebut menunjukkan hasil negatif kandungan hidrokuinon yang dapat dibuktikan dengan nilai Rf yang berbeda antara sampel uji dan baku hodrokuinon.

Meskipun penggunaan senyawa hidrokuinon dalam kosmetik masih diperbolehlan dengan pengawasan dan resep langsung dari dokter, namun adanya senyawa hidrokuinon pada kosmetika yang dijual bebas tersebut dilarang karna dapat menimbullkan bahaya bagi penggunanya, sedangkan senyawa merkuri sudah jelas tentang larangan penggunaan bahan tersebut dalam kosmetik sehingga hasil positif terhadap merkuri pada sampel yang diuji menunjukkan bahwa kosmetika tersebut beresiko besar terhadap kesehatan bagi pemakainya, baik dalam jangka waktu singkat maupun dalam jangka waktu yang lebih lama.

\section{KESIMPULAN}

1. Seluruh sampel mengandung senyawa merkuri.

2. Seluruh sampel negatif kandungan senyawa hidrokuinon. 
3. Dari data analisis yang telah dilakukan, seluruh sampel krim pencerah wajah tersebut tidak aman untuk digunakan karena mengandung merkuri.

\section{DAFTAR PUSTAKA}

${ }^{1}$ Badan Pengawas Obat dan Makanan. 2011. Persyaratan Tekhnis Bahan Kosmetik:

Keputusan Kepala Badan Pengawas Obat dan Makanan Republik Indonesia No. HK.00.03.1.23.08.11.07517.

${ }^{2}$ World Health Organization. 2011. Mercury In Skin Lightening Products. Public Health Andenvironment, Switzerland.

${ }^{3}$ Azhara \& Khasanah. 2011. Waspada Bahaya Kosmetik. FlashBooks. Jogjakarta.

${ }^{4}$ Parengkuan, K., Fatimawali, citraningtyas G. 2013. Analisis Kandungan Merkuri Pada Krim Pemuth Yang Beredar Di Kota Manado. PHARMACON Jurnal Ilmiah Farmasi - UNSRAT. Vol. 2 No. 01 Februari 2013 ISSN 2302 - 2493.

${ }^{5}$ Van Loon, J.C. 1980, Analytical Atomic Absorpsion Spectroscopy Selected Methods. New York: Academic Press.

${ }^{6}$ Connors, K.A. 1982. A Textbook of Pharmaceutical Analysis. New York: John Wiley \& Sons Inc. 